\title{
FUSÕES E AQUISIÇÕES COMO UM FEIXE DE CONTRATOS
}

\section{Sandro Vugman Wainstein* Silvio Bitencourt da Silva*}

Resumo: Este trabalho promove uma análise crítica de todas as etapas existentes no processo de F\&A e identifica os cuidados que os advogados devem levar em consideração ao elaborar os contratos, objetivando aumentar o percentual de sucesso das operações de F\&A de empresas. Aqui se apresenta um tipo de framework, composto por onze elementos de decisão, nomeado como "Canvas jurídico para uma operação de F\&A", desenvolvido para auxiliar os atores e, especialmente, os operadores do direito, a visualizarem de forma fácil e eficiente as principais etapas críticas de um processo de F\&A e os seus instrumentos jurídicos correlatos.

Palavras-chave: Aquisições; Contratos; Fluxo de Processos; Fusões; Operações; Canvas.

\section{MERGERS AND ACQUISITIONS AS A BUNDLE OF CONTRACTS}

Abstract: This work promotes a critical analysis of all the existing stages in the M\&A process and identifies the care that lawyers must take into account when drafting contracts, aiming increase the percentage of success of M\&A operations of companies. Here is presented a type of framework, composed of eleven elements of decision, named as "Legal canvas for an M\&A operation", developed to help the actors and, especially, the legal operators, to visualize in an easy and efficient way the main critical stages of an M\&A process and its related legal instruments.

Keywords: Acquisitions; Contracts; Fusions; Operations; Process Flow; Canvas.

\section{INTRODUÇÃO}

No âmbito dos negócios, o propósito de toda empresa é a criação de valor. Todavia, para criar valor, é necessário que a empresa cresça. A forma natural de uma empresa crescer é aumentando o número de clientes, as unidades vendidas e a participação no mercado. Isso é denominado crescimento orgânico, que pode ser um caminho sustentável, mas, ao mesmo tempo, mais lento para as empresas crescerem.

\footnotetext{
* Advogado. Graduado em Direito pela Pontifícia Universidade do Rio Grande do Sul. Especialista em Direito Tributário pelo Instituto Brasileiro de Estudos Tributário. Mestrando em Direito Profissional das Empresas e dos Negócios pela Universidade do Rio dos Sinos. E-mail: svwainstein@ gmail.com. Endereço para acessar este CV lattes: http://lattes.cnpq.br/4969836038705431.

* Doutorado em Administração de Empresas pela Universidade do Vale do Rio do Sinos - UNISINOS.

Atualmente exerce a função de professor do Mestrado Profissional em Direito da Empresa e dos Negócios e dos MBAs em Gestão nos campos da inovação e estratégia; e a função de Gerente de Pesquisa, Desenvolvimento e Inovação na Unidade Acadêmica de Pesquisa e Pós-Graduação da UNISINOS. E-mail:sibitencourt@ unisinos.br. Endereço para acessar este CV: http://lattes.cnpq.br/5792727067633222.
} 
Outra forma de crescimento é o inorgânico, mediante operações de Fusões \& Aquisições $(\mathrm{F} \& \mathrm{~A})^{1}$. Esse caminho geralmente permite que as empresas ampliem as suas posições de mercado, superem barreiras de entrada, obtenham escala de produção com menores custos, adquiram ativos estratégicos e se apropriem de novas tecnologias ou patentes de forma mais rápida do que seria possível no crescimento orgânico. Por essas razões, efetuar uma operação de fusão ou aquisição em vez de depender do crescimento orgânico faz sentido para uma empresa que pretende acelerar o seu crescimento.

Para todos os efeitos, F\&A significa, de forma genérica, uma combinação de negócios entre empresas, podendo ter variações do mesmo tema. No sentido mais estrito, uma fusão é uma união de duas ou mais empresas, resultando, ao final, em uma nova empresa. Fusões são mais raras de acontecer do que aquisições, pois dependem de uma série de fatores mais difíceis de se conjugarem. Uma aquisição, por sua vez, ocorre simplesmente quando uma empresa adquire outra, uma linha de produtos ou ativos estratégicos.

Sob o ponto de vista jurídico, uma operação de F\&A pode ser caracterizada como um processo guiado por um feixe (ou nexo) de contratos, os quais têm por objetivo regular a combinação de negócios e outras relações jurídicas conexas que exsurgem entre as partes, independentemente da forma jurídica adotada na operação.

Desde o início deste século, empresas brasileiras têm aumentado significativamente o número dessas transações, tanto no cenário nacional quanto no exterior (AMBINA, 2019; PwC Brasil, 2019). No entanto, F\&A representam operações complexas. Várias são as áreas de conhecimento aplicadas, tais como: direito, economia, administração, contabilidade, negociação, entre outras, sendo que nenhuma delas apresenta uma dominância ou legitimidade sobre as demais. Devido ao elevado grau de complexidade, riscos e incertezas, as operações de F\&A também dividem opiniões a respeito de suas vantagens e desvantagens.

Em especial, convém aos advogados que pretendem atuar no âmbito das operações de F\&A conhecer as diversas áreas do direito (societária, contratual, tributária, trabalhista, mercado de capitais, ambiental, regulatória, concorrencial e outras afins), para aplicá-las

\footnotetext{
${ }^{1}$ Existem diferentes formas de crescimento inorgânico para as sociedades empresariais. Cada uma pode ser adequada para determinada situação, dependendo do estágio em que se encontra o empreendimento, dos objetivos estratégicos, da situação de fluxo de caixa da sociedade, entre outras situações. Uma modalidade mais recente de captação de recursos determinante para o crescimento inorgânico de uma empresa pode ocorrer através da admissão na sociedade de um investidor de risco. São os casos de investimentos chamados pela expressão estrangeira de venture capital e de private equity. Este trabalho, contudo, tem como objetivo analisar as operações de fusões e aquisições como um meio de crescimento inorgânico.
} 
dentro de um pensamento estratégico e econômico. É evidente que não se dispensa a utilização de profissionais especialistas nessas áreas do direito sensíveis a cada operação.

O trabalho dos advogados de F\&A é bastante dinâmico e, sempre que possível, deve iniciar antes mesmo da elaboração dos contratos. A sua participação em todas as etapas do processo de F\&A é fundamental para melhor estruturar o negócio, avaliar os riscos, organizar o financiamento e coordenar a sequência de eventos para concluir a transação com êxito, evitando-se ao máximo litígios futuros entre as partes.

As tarefas dos advogados de F\&A incluem a elaboração de toda a rede de contratos relacionados às etapas da transação. Por exemplo, ao atuar na fase de negociação, devem elaborar com eficiência: acordos de confidencialidade (non-disclosure agreements - NDA), cartas de intenções (letters of intent - LOI) e memorandos de entendimentos (memorandums of understanding - MoU). Ao atuar na fase de fechamento do negócio, devem elaborar os chamados contratos definitivos de compra e venda (share ou stock purchase agreement SPA) e os acordos societários entre os novos sócios (shareholders agreement - SHA). Logo, as operações de F\&A sob o ponto de vista do direito representam um feixe de contratos que, embora distintos e autônomos, são interdependentes do ponto de vista funcional e econômico.

Este trabalho objetiva promover uma análise crítica de todas as etapas existentes no processo de F\&A e identificar os cuidados que os advogados devem levar em consideração ao elaborar os contratos. A finalidade dessa análise é de alocar e mitigar riscos de forma eficiente, bem como evitar litígios futuros e, por consequência, aumentar o percentual de sucesso das operações de F\&A de empresas.

Em virtude da proeminência das atividades de F\&A no mercado global, torna-se relevante entender a dinâmica dessas operações. Acrescenta-se, ainda, que o tema é substancial para o mundo acadêmico e profissional, já que a análise multidisciplinar dessas operações possui um papel importante para aprimorar a consciência dos gestores e demais partes interessadas envolvidas nesses processos, permitindo uma tomada de decisão consistente, estratégica e integrada, que maximize as chances de sucesso.

Este estudo, inicialmente, possui um caráter descritivo, à medida que é investigado o estado atual do conhecimento existente em torno da temática em enfoque mediante uma revisão da literatura sobre o assunto F\&A. Baseando-se nos fundamentos teóricos escolhidos, utiliza-se uma abordagem explicativa a fim de que sejam identificados os fatores 
determinantes sobre o fenômeno estudado, bem como produzidos os insumos para o delineamento das observações desejadas.

Com base em dados secundários (pesquisa bibliográfica, literatura publicada em livros, periódicos, publicações avulsas, impressas ou eletrônicas), devido ao sigilo natural que permeia as operações de F\&A e sem pretender esgotar os exemplos de nenhuma categoria, serão abordados alguns casos para aproximar a teoria da prática.

\section{DESENVOLVIMENTO DA PESQUISA}

\subsection{Fusões e Aquisições}

A fusão, ou consolidação, é a união de duas sociedades, geralmente de porte semelhante, que se combinam em uma simples permuta de ações ou quotas conforme o tipo jurídico adotado, dando origem a outra sociedade. Já a aquisição é a compra de uma sociedade por outra ou de ativos estratégicos, na qual somente uma delas irá permanecer com a sua identidade (ROSS; WESTERFIELD; JAFFE, 2015).

No âmbito da legislação nacional, tanto a Lei das Sociedades Anônimas (BRASIL, 1976) quanto o Código Civil (BRASIL, 2002) tratam as operações de F\&A como formas de reorganizações societárias.

De acordo com o artigo 228 da Lei das Sociedades Anônimas e o artigo 1.119 do Código Civil, a fusão é a operação pela qual se unem duas ou mais sociedades para formar sociedade nova, que lhes sucederá em todos os direitos e obrigações. Já a aquisição pode ocorrer, do ponto de vista societário, mediante a compra e venda de ações ou quotas já existentes ou de investimento direto, representados pela subscrição de novas ações ou quotas, bem como através das operações societárias de incorporação ou cisão - essa última nas modalidades total e parcial. Segundo o artigo 227 da Lei das Sociedades Anônimas e o artigo 1.116 do Código Civil, a incorporação é a operação pela qual uma ou mais sociedades são absorvidas por outra, que lhes sucede em todos os direitos e obrigações. Por sua vez, a cisão é a operação pela qual a companhia transfere parcelas do seu patrimônio para uma ou mais sociedades, constituídas para esse fim ou já existentes, extinguindo-se a companhia cindida, se houver versão de todo o seu patrimônio ou dividindo-se o seu capital, se a versão for parcial (artigo 229 da Lei das Sociedades Anônimas). 
Ao longo do tempo, o cenário das reorganizações societárias evoluiu com a edição da Lei $n^{\circ}$ 11.638/07 (BRASIL, 2007) e da Lei $n^{\circ}$ 11.941/09 (BRASIL, 2009) que introduziu no Brasil o chamado International Financial Reporting Standard - IFRS -, surgindo uma nova terminologia para se referir às reorganizações societárias como "combinação de negócios". Tal terminologia deu um caráter mais abrangente ao cenário das reorganizações societárias, englobando outras operações voltadas para a movimentação de ativos empresariais, mas que, por alguma razão, não necessariamente envolvem alterações societárias de maior repercussão (MUNIZ, 2011).

Nesse sentido, o Comitê de Pronunciamento Contábeis emitiu o Pronunciamento Técnico CPC 15, definindo o conceito de “Combinação de Negócios” (CPC, 2011)

Combinação de negócios é uma operação ou outro evento por meio do qual um adquirente obtém o controle de um ou mais negócios, independentemente da forma jurídica da operação. Neste Pronunciamento, o termo abrange também fusões e aquisições que se dão entre partes independentes (inclusive as conhecidas por true mergers ou merger of equals).

Com efeito, as operações de fusão, incorporação e cisão podem dar forma jurídica às estruturações de uma transação de F\&A ou, ainda, servir de mecanismos auxiliares para a compra e venda de participação societária ou subscrições de novas ações ou quotas. Também podem ser utilizadas para a criação de estruturas empresariais, segregação de negócios, planejamento tributário, entre outras possibilidades.

Cabe salientar que as operações de F\&A são negócios jurídicos ocorridos entre pelo menos duas sociedades, cujo objeto é a transferência de um conjunto de bens, direitos e obrigações por, ao menos, uma das sociedades envolvidas a outra ou a uma nova que venha a surgir a partir da operação, por sucessão. A definição de sucessão é de extrema importância para a análise das consequências atinentes à transferência de passivos "ocultos" ou não das empresas envolvidas nesse tipo de negociação, tendo em vista que nessa operação não carregam somente os ativos da(s) empresa(s) envolvida(s), mas também as suas obrigações (fiscais, trabalhistas, ambientais e afins), o que certamente influencia no preço e nas condições do negócio a ser implementado.

De acordo com Ross, Westerfield e Jaffe (2015) e Weston e Brigham (2000), uma fusão ou uma aquisição podem ser classificadas em quatro categorias: horizontais, verticais, conglomerado e congênere. Essas são categorias distintas, mas que expressam as razões pelas quais duas empresas devem valer mais juntas do que separadas (BREALEY; MYERS, 2006). 


\subsubsection{Motivações}

As motivações para uma operação de F\&A são uma questão fundamental para a compreensão do tema, pois estão intrinsecamente ligadas ao processo que envolve as decisões estratégicas que viabilizam ou não as transações.

No campo acadêmico, há uma infinidade de motivações e não parece haver um consenso absoluto a respeito delas. Firth (1980) discorre sobre duas correntes teóricas que podem ser utilizadas para justificar os motivos pelos quais as empresas se envolvem em uma operação de F\&A. A primeira, denominada como teoria neoclássica da maximização dos lucros da firma, parte do pressuposto de que as forças do mercado são as motivações para que os gestores tomem decisões que maximizem o valor das firmas e a riqueza dos acionistas. Assim, as firmas irão optar pelo engajamento em processos de F\&A se eles resultarem em geração de valor para os acionistas, seja em decorrência de sinergias criadas, de aumento do poder de monopólio ou pela substituição de gestores ineficientes. Já a segunda, conhecida como teoria da maximização da utilidade gerencial, possui como pressuposto que os gestores irão priorizar seus interesses pessoais para, então, satisfazer a necessidade de geração de riqueza imposta pelos acionistas. Logo, os gestores tentarão maximizar sua utilidade gerencial, buscando mecanismos que reduzam o risco de perderem seus empregos e aumentem os seus salários, o poder e a satisfação no trabalho, além de garantir um nível satisfatório de lucros para os acionistas.

Embora sejam complexos e frequentemente apareçam em conjunto (ANGWIN, 2001), Johnson, Scholes e Wittington (2007) sintetizam em três os tipos de motivações para realização de operações de F\&A: estratégicas, financeiras e gerenciais. As motivações estratégicas estão focadas em aprimorar e desenvolver o negócio e relacionadas à obtenção de vantagem competitiva no mercado. As motivações financeiras são aquelas incentivadas pela exigência de retorno pelos acionistas e pela necessidade de promover uma melhoria na performance financeira da sociedade empresária. Por fim, as motivações gerenciais são fruto dos interesses dos diretores e não necessariamente refletem os interesses dos acionistas.

A literatura apresenta diversos motivos para as F\&As, listados no Quadro 1.

Quadro 1 - Motivos para Fusões \& Aquisições

\begin{tabular}{|l|l|}
\hline Expectativas assimétricas & $\begin{array}{l}\text { Diferentes expectativas sobre o futuro levam os investidores a atribuírem valores } \\
\text { diferentes a uma mesma firma, ocasionando propostas de compra. }\end{array}$ \\
\hline
\end{tabular}




\begin{tabular}{|c|c|}
\hline $\begin{array}{l}\text { Irracionalidade individual } \\
\text { nas decisões de dirigentes }\end{array}$ & $\begin{array}{l}\text { Justificativa hipotética para as fusões, segundo a qual, sob condições de } \\
\text { incerteza, os indivíduos nem sempre tomam decisões racionais. Irracionalidades } \\
\text { diluídas ou anuladas quando consideradas de forma agregada na interação dos vários } \\
\text { agentes econômicos. }\end{array}$ \\
\hline $\begin{array}{l}\text { F\&A como uma } \\
\text { alternativa a dividendos e } \\
\text { recompra de ações }\end{array}$ & Situação presente em firmas com fluxos de caixa livres. \\
\hline $\begin{array}{l}\text { Compensações e } \\
\text { incentivos tributários }\end{array}$ & $\begin{array}{l}\text { Advindos de créditos tributários, relativos a prejuízos acumulados por uma das } \\
\text { firmas envolvidas poderem ser compensadas em exercícios futuros pela outra firma } \\
\text { que venha apresentando lucros. }\end{array}$ \\
\hline $\begin{array}{l}\text { Custos de reposição e } \\
\text { valores de mercado }\end{array}$ & $\begin{array}{l}\text { Situação existente quando os custos de reposição dos ativos de uma firma forem } \\
\text { maiores que o seu valor de mercado. Isto é, quando a razão "Q de Tobin" de uma da } \\
\text { firma for menor do que a unidade ("Q de Tobin" }<1 \text { ). }\end{array}$ \\
\hline $\begin{array}{l}\text { Sinergias operacionais e } \\
\text { gerenciais }\end{array}$ & $\begin{array}{l}\text { Advindas de possíveis reduções nos custos em função do aumento do nível de } \\
\text { produção, maior racionalização do esforço de pesquisa e desenvolvimento, uso } \\
\text { conjunto de insumos específicos não divisíveis e transferência de tecnologia e } \\
\text { conhecimento }(\text { know-how). }\end{array}$ \\
\hline $\begin{array}{l}\text { Efeitos anticompetitivos e } \\
\text { busca do poder de } \\
\text { monopólio }\end{array}$ & $\begin{array}{l}\text { Advindos de ganhos com o aumento da concentração de mercado e da } \\
\text { consequente redução da competição. }\end{array}$ \\
\hline $\begin{array}{l}\text { Redução do risco de } \\
\text { insolvência }\end{array}$ & $\begin{array}{l}\text { Advinda da fusão entre duas ou mais firmas com fluxos de caixa sem correlação } \\
\text { perfeita (F\&As conglomerado e cosseguro). }\end{array}$ \\
\hline Razões gerenciais & $\begin{array}{l}\text { As F\&As podem ocorrer visando tanto ao aumento do bem-estar dos diretores das } \\
\text { firmas, mesmo que a operação cause impacto negativo no valor de mercado de suas } \\
\text { ações, como à substituição de diretores que não estejam maximizando o valor de } \\
\text { mercado de suas firmas. }\end{array}$ \\
\hline
\end{tabular}

Fonte: Gort (1969), Jensen (1986), Kloeckner (1994), Manne (1965), Mueller (1969), Roll (1986), Scherer e Ross, Westerfield e Jaffe (2015).

Um motivo em comum emerge de todas as vertentes: a criação de valor por meio da exploração eficiente de sinergias entre as sociedades empresárias envolvidas. Segundo Damodaran (2005) sinergia é o valor adicional gerado pela combinação de duas empresas, criando oportunidades que não estavam disponíveis para elas quando operavam de forma independente. De fato, não obstante os ganhos de sinergia serem em grande parte a motivação central das fusões e aquisições, é importante que outras motivações estratégicas, tais como a capacidade de inovação, sejam objeto de análise e discussão dentro do processo de F\&A. Isso se deve ao fato de que a captura de sinergias, ainda valiosa, tem se tornado mais difícil de se concretizar em função das rápidas mudanças na dinâmica do ambiente de negócios. Por exemplo, no ano de 2015, a gigante AMBEV adquiriu a empresa mineira de cervejas artesanais Wäls com a finalidade de acelerar o desenvolvimento de inovações nesse setor (BOUÇAS, 2015). Um motivo financeiro pouco explorado pela literatura sobre o assunto 
refere-se ao desinvestimento (BOUÇAS, 2015). Como resultado, empresas podem frequentemente adquirir outras sem pagar um grande prêmio (GHEMAWAT; GHADAR, 2000; LAAMANEN; BRAUER; JUNNA, 2014)

\subsubsection{Etapas ou fases de uma operação de $F \& A$}

Reed, Lajoux e Nesvold (2007) dividem as operações de F\&A nas seguintes principais etapas ou fases, a seguir selecionadas: planejamento, identificação, due diligence, avaliação do alvo, negociação, fechamento e integração. Anterior à tomada da decisão de adquirir uma empresa ou efetuar uma fusão, os gestores devem ter de forma clara os objetivos e a estratégia empresarial de suas intenções: o que, como e quando comprar; com quem, quando e como se devem associar. Em síntese, com a finalidade de dirimir tais questionamentos, cabe descrever, ainda que de forma sucinta, as chamadas etapas e fases de uma operação de F\&A.

1) Planejamento: Nessa primeira fase, são previamente definidos os objetivos a alcançar com a operação de F\&A, determinando-se qual o setor de atividade, qual a empresa pretendida, qual o momento oportuno e qual a forma de realização da operação. São também identificados riscos potenciais e definidas as linhas de atuação;

2) Identificação: $\mathrm{Na}$ segunda fase, é realizado um levantamento exaustivo das empresas-alvo, sobre as quais serão feitas diversas análises e se selecionará a melhor opção para a empresa adquirente ou vendedora. As compradoras procuram por vezes a ajuda de instituições financeiras ou intermediários, sendo que as vendedoras procuram investidores e compradores interessados em seus ativos (DePAMPHILIS, 2003).

3) Auditoria (Due diligence): De acordo com ELSON (2009), a fase da auditoria (contábil, fiscal, societária, ambiental, cultural e etc.), pode fazer a diferença entre o sucesso ou fracasso de uma operação de F\&A.

4) Avaliação (Valuation) - Na quarta fase, é iniciado o processo de avaliação da empresa-alvo. Entre a vasta literatura sobre valuation, os autores adotam recortes diferentes para classificar os tipos de métodos existentes. Como não é o objetivo deste trabalho aprofundar-se nesse tema, mas propor apenas uma reflexão sobre as consequências de uma precificação falha, destaca-se três das metodologias mais praticadas no mercado: fluxo de caixa descontado, múltiplos e valor de mercado.

5) Negociação: A negociação está presente em todas as fases ou etapas de um processo de F\&A, mas na quinta fase é comum dar-se ênfase nela, pois é nesse momento que 
se coloca em discussão a efetiva estruturação do negócio, a formulação do preço e seus mecanismos de ajustes, as cláusulas de indenização, as soluções de controvérsias, a melhor estrutura societária, tributária, entre diversos outros aspectos.

6) Fechamento (Signing/Closing): $\mathrm{Na}$ sexta fase, são elaborados os termos dos contratos definitivos de compra e venda (share ou stock purchase agreement - SPA) e os acordos societários entre os novos sócios (shareholders agreement-SHA).

7) Integração (Post Merger Integration - PMI): Na sétima fase, uma vez consumada a operação, uma nova etapa se inicia, na qual são definidas várias premissas de atuação: (i) ajustamento dos produtos e de mercados; (ii) mudança na equipe diretiva; (iii) ajustamento das atividades da empresa (área comercial, de produção, financeira, pessoal etc.); (vi) definição da estratégia empresarial a seguir no futuro, tendo em atenção a situação pósfusão ou aquisição.

\subsection{O processo de F\&A como um feixe de contratos}

Para Coase (1995) as empresas são feixes de contratos que organizam atividades econômicas visando à redução de custos de transação de operar em mercados. Isto é, uma empresa pode ser vista a partir das inúmeras relações contratuais que ela celebra constantemente, quer seja com seus empregados ou com seus clientes e fornecedores.

Assim, uma operação de F\&A pode ser caracterizada como um processo guiado por um feixe (ou nexo) de contratos, que tem por objeto regular a combinação de negócios e outras relações jurídicas conexas que exsurgem entre as partes, independentemente da forma jurídica adotada na operação (COELHO, 2000). Esse feixe, ou nexo, de contratos se estabelece em cada uma das etapas existentes no processo de F\&A, pois uma operação dessa natureza é composta por várias fases, desde aproximação entre as partes, trocas preliminares de informações e assinatura de documentos iniciais, passando pela auditoria (due diligence) até o fechamento da transação (LUIZE, 2016).

É fato que existe aquele que é conhecido em regra geral como o instrumento central de qualquer operação de F\&A, pois sem ele a transação não se concretiza: o chamado Contrato de Compra e Venda de Ações ou Quotas Representativas de Capital Social (CCVA ou SPA share/stock purchase agreement) (BOTREL, 2014). Contudo, deve-se levar em consideração os demais instrumentos jurídicos que surgem no decorrer de uma operação de F\&A. Esses instrumentos jurídicos permitem o desenvolvimento bem-sucedido da operação, uma boa 
integração e o sucesso do negócio segundo as motivações e os objetivos pretendidos e pactuados entre as partes, desempenhando papel essencial ao fixar diretrizes e, consequentemente, possibilitar o entendimento das razões subjacentes de cada uma das provisões pactuadas no CCVA ou SPA (REED, 2007).

Nesse contexto, é comum que anteriormente ao instrumento jurídico principal (CCVA ou SPA) sejam pactuados pelas partes uma série de outros documentos jurídicos, conhecidos no mundo corporativo como: carta de intenções (letter of intent - LOI), memorando de entedimentos (memorandum of understanding - MoU) ou ainda o acordo de investimento (term sheet). Em seguida, a parte compradora deverá proceder a uma auditoria (due diligence) da empresa-alvo (target), mediante a assinatura prévia de um acordo ou termo de confidencialidade chamado non-disclosure agreement (NDA), diante da necessidade de trocas de informações sensíveis e sigilosas entre as partes. Após, com a realização da avaliação (valuation) da empresa-alvo, as partes iniciam um processo de negociação e, havendo consenso nas tratativas negociais, seus termos são reproduzidos em linguagem jurídica no mencionado CCVA ou SPA para, então, por fim, ser firmado o denominado acordo de acionistas (shareholders agreeement - SHA) ou de quotistas, citando-se aqui os mais usuais utilizados no decorrer das etapas do processo de F\&A (BOTREL, 2016)

Muito embora o emprego de expressões estrangeiras deve ser evitado em trabalhos científicos, como prelecionam os doutrinadores mais tradicionais, o conhecimento da terminologia em língua inglesa se faz necessário, pois tais expressões sao comumente utilizadas por quem tem contato na prática com as operações de F\&A. Preparados, na maioria das vezes, sob forte influência de países de origem e tradição jurídica na Commom Law (eixo Nova Iorque-Londres), onde se processa a maioria das operações de maior expressão, o operador do direito deve tomar cuidado e levar em consideração a legislação brasileira aplicável. Desse modo, contratos bem-planejados podem ser um meio importante e eficiente para os advogados adicionarem valor aos serviços prestados aos seus clientes, atuando como "engenheiros de custos de transação", na concepção de Gilson (1995).

Seguindo essa mesma linha, Williamson (1993) considera que a redução dos custos de transação é uma função essencial na economia e, em grande parte, é desenvolvida no âmbito jurídico. No entanto, a atuação advocatícia não se encerra nesse âmbito. A sua contribuição na solução de problemas percebidos nas transações de F\&A permite que clientes assumam formas adicionais de riscos (negativos e/ou positivos), e, assim, são exercidas novas 
atividades criadoras de riqueza (COATES, 2012). Em particular, Gilson sugere que os advogados de negócios devem projetar "mecanismos eficientes" para conter o oportunismo, a aversão a risco, as informações imperfeitas e outras fontes de "fricção" econômica (1984).

Seja em âmbito nacional ou em um negócio transfronteiriço (crossborder), as operações de F\&A dependem de uma detalhada análise jurídica. Questões como sigilo, exclusividade, processo de auditoria (due diligence), práticas anticoncorrenciais, direitos e responsabilidades de cada parte envolvida, devem ser cuidadosamente examinadas no decorrer de todo o processo em questão.

Portanto, o advogado deve participar durante início, meio e fim de uma operação de F\&A. Ou seja, desde a negociação inicial entre as partes, mediante a elaboração ou análise dos documentos preliminares (LOI, MoU ou term sheet e NDA), bem como na auditoria legal nas diversas áreas do direito, até o seu fechamento com a confecção ou exame dos contratos principais ou definitivos (contrato de aquisição e acordo de acionistas) e na fase de pósfechamento, com a consolidação da transação.

\subsubsection{Carta de Intenções (Letter of Intent - LOI)}

Os processos de F\&A geralmente iniciam pelo contato informal entre as partes, através de uma simples troca de informações com o propósito de medir o apetite e verificar se o negócio será comercialmente proveitoso para as partes. Essa fase, conhecida como "namoro", resulta na criação de documentos preliminares que sintetizam a transação que irá ocorrer ou o negócio que irá se formar. Esses documentos preliminares são muito importantes para que o processo negocial evolua com clareza, rapidez e objetividade.

Nessa fase inicial, aparecem com maior frequência três tipos de documentos: a carta de intenção - também chamada de LOI, do inglês letter of intent —, o memorando de entendimentos - também chamado de MoU, do inglês memorandum of understanding - e o acordo de investimento — também conhecido como term sheet.

A LOI é empregada quando há uma transação em vista, mas ainda não há o conhecimento necessário da parte interessada sobre as condições da empresa a ser adquirida ou investida. Na prática, a assinatura desse documento traz um certo conforto e uma segurança para ambas as partes, pois, antes de trocarem informações sensíveis e sigilosas, bem como incorrerem em altos custos na contratação de especialistas das mais diversas áreas para a realização da necessária due diligence (auditorias legais, contábeis, financeiras etc.), 
para a avaliação da(s) empresa(s) envolvida(s) na negociação e para a confecção dos instrumentos jurídicos, formaliza a intenção mútua com relação à potencial transação.

Já o chamado MoU — apesar de ser similar à carta de intenções — na maioria das vezes é utilizado quando se pretende criar uma nova empresa (Joint Venture) ou celebrar negócios conjuntos, hipóteses que se distanciam em parte de uma transação de fusão ou aquisição. Assim, esse documento estabelece condições mais abrangentes para duas empresas entrarem em acordo operacional.

Por sua vez, o acordo de investimento, ou term sheet, detalha os termos legais e financeiros do investimento e quantifica, em números e outros indicadores, o valor da transação. A estrutura de um term sheet tende, portanto, a ser mais complexa e abrangente do que a de uma LOI.

Com efeito, importante destacar que os termos e condições vinculantes previstos nestes instrumentos geram direitos e obrigações às partes, e as boas práticas sugerem, inclusive, que sejam espelhados na documentação definitiva, uma vez concretizada a operação. Os não vinculantes não criam direitos ou obrigações para os envolvidos, mas não deixam de ser relevantes para que o processo negocial evolua com clareza, rapidez e objetividade.

Apesar de ser a etapa inicial de um processo de F\&A, sob a perspectiva legal, trata-se de uma das fases críticas, pois tais documentos assumem a natureza jurídica de contrato preliminar ou pré-contrato, que poderá vincular as partes e acarretar, como consequência, o direito à celebração do contrato definitivo, nos termos do artigo 463 do Código Civil:

Art. 463. Concluído o contrato preliminar, com observância do disposto no artigo
antecedente, e desde que dele não conste cláusula de arrependimento, qualquer das
partes terá o direito de exigir a celebração do definitivo, assinando prazo à outra
para que o efetive (BRASIL, 2002).

Nesse sentido, uma vez levado a registro no órgão competente, o juiz poderá, desde que a pedido do interessado e com vistas a suprir a vontade da parte inadimplente, conferirlhe caráter de definitivo ou poderá, a pedido da parte estipulante, considerá-lo desfeito e solucionar a questão através da apuração de eventuais perdas e danos, segundo estipulam os artigos 464 e 465 do Código Civil (BRASIL, 2002): 
Art. 464. Esgotado o prazo, poderá o juiz, a pedido do interessado, suprir a vontade da parte inadimplente, conferindo caráter definitivo ao contrato preliminar, salvo se a isto se opuser a natureza da obrigação.

Art. 465. Se o estipulante não der execução ao contrato preliminar, poderá a outra parte considerá-lo desfeito, e pedir perdas e danos.

Por essas razões é que na prática se constata que a maior parte das cláusulas desses instrumentos preliminares são não vinculantes e em menor quantidade vinculantes (REED, 2007), não obstante determina o artigo 427 do Código Civil (BRASIL, 2002), estipula que a proposta de contrato obriga o proponente, se o contrário não resultar dos termos dela, da natureza do negócio, ou das circunstâncias do caso.

Há, portanto, uma presunção de boa-fé de que as disposições contidas na LOI estarão refletidas nos documentos definitivos, de modo que, negocialmente, se uma parte pretender alterar as bases da negociação assentadas na LOI, é possível que a outra exija compensações negociais importantes ou até o fim das negociações, em que se dirá que houve uma situação deal breaker, conhecido como o fator que impede a conclusão de uma negociação (ALMEIDA, 2009).

\subsubsection{Acordo de Confidencialidade (Non-Disclosure Agreement - NDA)}

O processo de F\&A envolve uma série de troca de informações, em especial, informações confidenciais da empresa-alvo. $\mathrm{O}$ acordo de confidencialidade, ou simplesmente NDA - como é conhecido no mundo corporativo - é um instrumento jurídico fundamental, cuja importância não deve ser subestimada.

Por isso, é recomendável que as partes, antes de iniciarem as etapas de due diligence e/ou valuation, assinem um NDA, objetivando ajustar as condições de fornecimento das informações consideradas confidenciais, bem como definir as regras relativas ao uso e proteção, evitando-se, assim, o vazamento ou a utilização indevida por uma das partes.

Ainda que frequente a previsão de uma cláusula de confidencialidade, desde a pactuação da carta de intenções (LOI), a assinatura de um NDA com os detalhes sobre o alcance da confidencialidade das informações prestadas entre as partes e as regras de sua utilização têm demonstrado ser de importante valia para assegurar o intenso fluxo de informações sensíveis a serem trocadas durante o processo de F\&A.

Com relação às partes e o seu alcance, as informações consideradas como confidenciais deverão ser trocadas e usadas exclusivamente para os contratos e negócios que 
envolvem a operação e não poderão ser distribuídas, reveladas ou divulgadas de modo algum a terceiros, exceto para seus empregados, prepostos, colaboradores ou terceiros que tenham necessidade justificada de ter seu conhecimento e que, previamente, estejam obrigados à confidencialidade por compromisso formal.

Já quanto à definição das "informações confidenciais", salvo aquelas que sejam de domínio ou conhecimento público, são consideradas confidenciais toda e qualquer informação revelada por uma à outra ou vice-versa, contendo ela ou não a expressão "confidencial", incluindo-se, sem implicar em limitação, técnicas, know-how, especificações, designs, desenhos, cópias, diagramas, fórmulas, modelos, amostras, fluxogramas, croquis, fotografias, plantas, discos, contratos, planos de negócios, processos, projetos, conceitos de produto, amostras de ideias, clientes, nomes de revendedores e/ou distribuidores, preços e custos, definições e informações mercadológicas, softwares, algoritmos, invenções e ideias, outras informações técnicas, financeiras ou comerciais, entre outras.

No tocante ao dever das partes em manter a confidencialidade, cabe àquela que receber qualquer informação confidencial obrigar-se a manter o mais absoluto sigilo com relação a toda e qualquer informação dessa natureza, não podendo, sob qualquer pretexto, divulgar, revelar, reproduzir ou dar conhecimento a terceiros de tudo o quanto disser respeito aos respectivos segredos de negócio, devendo ser tratadas como estritamente confidencial.

Outro importante ponto a ser observado em um NDA são as sanções aplicáveis em caso de uso indevido de qualquer uma das informações classificadas como confidenciais. Nesse caso, é comum a previsão de que o descumprimento de qualquer obrigação prevista no NDA por uma das partes e/ou por um de seus diretores, empregados e/ou prepostos sujeitará ao pagamento de multa pecuniária, sem prejuízo do ressarcimento de todas as perdas e danos sofridos pela parte reveladora, nos termos do artigo 186 c/c 927 do Código Civil, inclusive as de ordem moral ou concorrencial, bem como as de responsabilidades civil e criminal respectivas, as quais serão apuradas em regular processo judicial ou administrativo.

O prazo de validade de um acordo de confidencialidade pode ser estipulado de forma indeterminada ou por um tempo razoavelmente determinado; porém, é prudente constar no NDA que todas as obrigações das partes sobrevivem ao seu término por qualquer motivo ou a sua rescisão, principalmente com relação à não divulgação ou ao seu uso, permanecendo em vigor e exigível a qualquer tempo, concretizada ou não, a possível transação. Ao contrário da 
LOI, todas as regras previstas no NDA devem ser de caráter eminentemente vinculante, para obrigar as partes ao seu cumprimento.

\subsubsection{Contrato de Aquisição de Ações (Share Purchase Agreement - SPA)}

Todas as etapas e instrumentos precedentes (carta de intenções, memorando de entendimentos ou term sheet) e o acordo de confidencialidade (auditorias e avaliação) trazem reflexos e especificidades ao desenho da operação, que se formaliza pelo contrato (SPA). Não existe um contrato de F\&A padrão, pois cada operação é única.

\subsubsection{Acordo de Sócios (Shareholders Agreement - SHA)}

Além do SPA, um documento que deverá constar entre os definitivos é o acordo de sócios (SHA), acionistas ou quotistas, dependendo do tipo jurídico adotado pela sociedade. Os SHA deverão ser observados pela sociedade e seus sócios quando arquivados na sua sede (BRASIL, 1976). Nas palavras de Carvalhosa (2004):

Trata-se, o acordo de acionistas, de um contrato submetido às normas comuns de
validade e eficácia de todo o negócio jurídico privado, concluído entre acionistas
da mesma companhia, tendo por objeto a regulação do exercício dos direitos
referentes às suas ações, tanto no que concerne ao controle como ao voto dos
minoritários ou, ainda, à negociabilidade dessas ações.
Tais acordos visam à composição dos interesses dos acionistas com respeito ao
exercício de seus direitos politicos, junto à companhia, e patrimoniais sobre suas
ações.

Justifica-se a existência de um SHA, na hipótese de a alienação das participações societárias (ações ou quotas) não ser realizada em sua totalidade, de sorte que às partes cabe regular os aspectos jurídicos que nortearão as futuras relações como sócios.

A construção de um SHA leva em conta uma série de particularidades da sociedade e de interesse de seus sócios. Temas sensíveis que deverão ser tratados com a maior parcimônia e especificidades envoltas.

\section{CANVAS JURÍDICO PARA UMA OPERAÇÃO DE F\&A}

Aqui se apresenta um tipo de framework, batizado como "Canvas jurídico para uma operação de F\&A", uma ferramenta de planejamento jurídico desenvolvida estrategicamente para auxiliar os atores e, especialmente, os operadores do direito, sobre aspectos críticos que impactam no sucesso ou fracasso de uma transação de F\&A. 
O mapa visual apresenta onze blocos:

(a) Planejamento: as motivações de uma operação de F\&A é uma das questões fundamentais para a compreensão de todo o processo, pois está intrinsecamente ligada às decisões estratégicas que viabilizam ou não as transações dessa natureza.

(b) Identificação: com a definição dos objetivos a alcançar, será feito um levantamento de diversas empresas e se selecionará a melhor (alvo ou target) sobre os quais serão feitas diversas análises.

(c) Carta de Intenções (LOI, MoU ou Term Sheet): documento preliminar de importância para a aproximação das partes e para que o processo de F\&A evolua com clareza, rapidez e objetividade (binding $x$ non-biding).

(d) Acordo de Confidencialidade (NDA): documento imprescindível para assegurar às partes a troca de informações sigilosas e sensíveis, de maneira estritamente confidencial, evitando-se a sua malversação.

(e) Auditoria (Due Diligence): apuração dos passivos e riscos materializados ou não, e definição das áreas a serem examinadas: societária, tributária, ambiental, regulatória, cultural, dentre outras.

(f) Avaliação (Valuation): entendimento das metodologias de valuation para apuração do valor justo (fair value) da operação.

(g) Negociação: estruturação do negócio (deal), discussão sobre o preço, seus ajustes e formas de pagamento, controle de conflitos e gestão de deal breacker.

(h) Método de Negociação: sugere-se a adoção do método de Harvard, baseado em princípios e a utilização da matriz de negociação complexa (MNC).

(i) Contrato de Aquisição (SPA): instrumento fundamental para a concretização da operação e atentamento de suas cláusulas e condições para o sucesso do negócio.

(j) Integração: elaboração de um plano de integração e seus fatores chaves.

(k) Acordo de Sócios (SHA): definição da condução das matérias deliberativas de condução dos negócios da sociedade e a relação entre os sócios.

Quadro 2 - Canvas jurídico para uma operação de F\&A 


\section{FUSÕES E AQUISIÇÕES COMO UM FEIXE DE CONTRATOS}

\section{Planejamento}

Razões estratégicas: aumento da fatia de mercado; eliminação de um concorrente; entrada em novos mercados ou segmentos de atividades; redefinição do foco com a venda de unidade de negócios não correlatas, aquisição de um fornecedor ou cliente chave, internacionalização, melhoria de imagem (ex. aquisição marca conhecida); reestruturação societária, entrada/saída de sócios, aquisição de uma "opção real", compra de algo hoje que possa gerar vantagem competitiva no futuro; aumento do tamanho da companhia para reduzir as possibilidades de falência (teoria do too big to fail).

Razões econômicas: economia de escala e ampliação do leque de produtos.

Razões financeiras: aumento da receita e fluxos de caixa livre; redução da dívida, através do aporte de novo capital e o melhoramento do rating.

Razões fiscais: possibilidade de o comprador aproveitar o prejuízo acumulado na companhia adquirida e a oportunidade de gerar maior vantagem fiscal.

\begin{tabular}{l} 
Identificação (Target) \\
\hline Levantamento da empresa-alvo, sobre as \\
quais serão feitas diversas análises e se \\
selecionará a melhor opção.
\end{tabular}

Carta de Intenções (LOI)

Binding $x$ Non-Biding

Por se tratar de um documento preliminar, deve se evitar a inclusão de termos e condições vinculantes. Termos e condições não vinculantes não criam direitos ou obrigações para as partes, mas não deixam de ser relevantes para que o processo negocial evolua com clareza, rapidez e objetividade.

\section{Termo de Confidencialidade (NDA)}

Instrumento jurídico, cuja importância não deve ser subestimada. Importante assegurar às partes, antes de iniciar a troca de informações sensíveis: definir o que são informações confidenciais, formas de fornecimento e devolução; sanções em caso de uso indevido; e o prazo de vigência.

\begin{tabular}{|c|c|}
\hline Auditoria (Due Diligence) & Negociação \\
\hline $\begin{array}{l}\text { Apurar os passivos e riscos } \\
\text { de contingências para } \\
\text { facilitar o processo de } \\
\text { negociação. } \\
\text { Dependendo do segmento e } \\
\text { da atividade praticada pela } \\
\text { empresa alvo, deverão ser } \\
\text { definidas as áreas } \\
\text { determinantes } \\
\text { procedimentos de due } \\
\text { dilingence: } \\
\text { tributária, societária, } \\
\text { trabalhista, }\end{array}$ & $\begin{array}{l}\text { A negociação está presente } \\
\text { em todas as fases, mas } \\
\text { após a auditoria e valution, } \\
\text { ela ganha um destaque } \\
\text { especial, pois se coloca em } \\
\text { discussão a estruturação } \\
\text { do deal, a formulação de } \\
\text { preços e seus ajustes, } \\
\text { causas de indenização, o } \\
\text { controle de conflitos e } \\
\text { controvérsias, a melhor } \\
\text { estrutura societária e } \\
\text { tributária da operação. }\end{array}$ \\
\hline regulatória, ambiental, & Método de Negociação \\
\hline Avaliação (Valuation) & $\begin{array}{l}\text { O método de Harvard } \\
\text { demonstra ser uma técnica }\end{array}$ \\
\hline $\begin{array}{l}\text { Entendimento das } \\
\text { metodologias de valuation: } \\
\text { fluxo de caixa descontado, } \\
\text { análise de transações } \\
\text { comparáveis e análise de } \\
\text { empresas. Definição do valor } \\
\text { justo (fair value) da } \\
\text { operação. }\end{array}$ & $\begin{array}{l}\text { que se adequa à negociação } \\
\text { de uma transação de F\&A. } \\
\text { Baseado em sólidos } \\
\text { princípios auxilia as partes a } \\
\text { encontrarem soluções para } \\
\text { os impasses que surgem no } \\
\text { decorrer da estruturação da } \\
\text { operação. Utilização da } \\
\text { matriz de negociação } \\
\text { complexa (MNC). }\end{array}$ \\
\hline
\end{tabular}

$\frac{\text { Integração (PMI) }}{\text { A elaboração de um plano de }}$ integração é um dos fatores chaves para o sucesso de uma operação. $\mathrm{O}$ timing de todo o processo de PMI, a forma de comunicação e as premissas de atuação devem ser previamente definidas, tais como, a estratégia empresarial a seguir, $o$ ajustamento dos produtos e de mercados, a convergência de processos e sistemas, os incentivos aos colaboradores, dentre inúmeros outros fatores.

\section{Acordo de Sócios (SHA)}

Define as principais matérias deliberativas de condução do negócio e a relação entre os sócios. Disposições usais: (i) cláusulas relativas a voto; (ii) administração da sociedade; (iv) alienação e aquisição de ações ou quotas (first offer e first refusal, shotgun, drag e tag-along; lockup, put e call option).

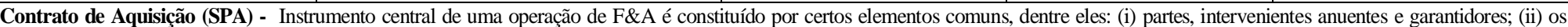

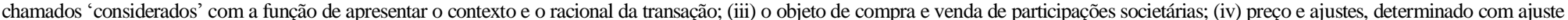

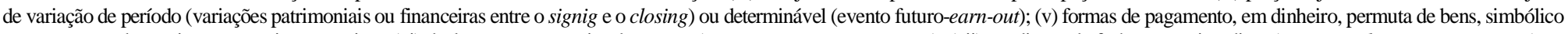

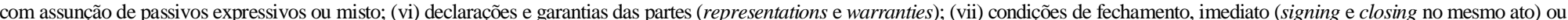

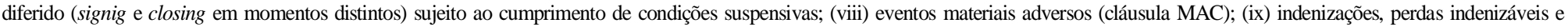

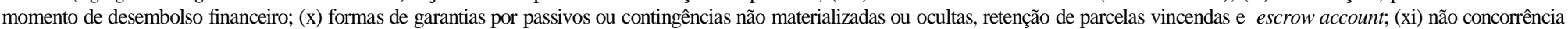

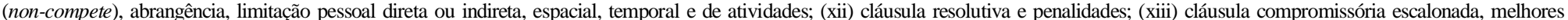
esforços, mediação e arbitragem.

Fonte: Elaborado pelos autores. 


\section{CONSIDERAÇÕES FINAIS}

Fusões e aquisições (F\&A) são eventos complexos. As operações de F\&A são intensamente estudadas por acadêmicos no campo das finanças, economia e estratégias corporativas. O presente trabalho aborda esta temática, desenvolvendo uma estrutura conceitual, que integra perspectivas teóricas nas mencionadas áreas de atuação e, em especial, no campo jurídico, para oferecer um modelo integrativo orientado a promover o sucesso de uma operação dessa natureza.

A compreensão do processo de F\&A como um feixe de contratos, ou nexo de contratos, que se estabelece nas etapas existentes no processo de $\mathrm{F} \& \mathrm{~A}$, desde a aproximação entre as partes, com a troca inicial de informações e a assinatura prévia de documentos preliminares (carta de intenções, memorando de entendimento ou term sheet e acordo de confidencialidade), passando pelos diferentes tipos de auditoria (due diligence), métodos de avaliação (valuation) até o fechamento da transação com a elaboração dos instrumento jurídicos definitivos (contrato de aquisição de ações/quotas e acordo de sócios), demonstra ser um fator determinante no tocante ao papel dos advogados quanto à mitigação e alocação de riscos, à redução de custos de transação e à criação de valor nessas operações.

Como resultado dos apontamentos e reflexões realizados neste estudo, o autor idealizou um framework, que denominou como: “Canvas jurídico para uma operação de F\&A”. Essa ferramenta foi desenvolvida objetivando auxiliar os atores e, especialmente, os operadores do direito, a visualizarem de forma fácil e eficiente as principais etapas críticas de um processo de F\&A e os seus instrumentos jurídicos correlatos.

Finalmente, sugestiona-se como estratégia de futuras pesquisas a técnica de estudo de caso com o viés de contemplar análises pormenorizadas de operações de F\&A.

\section{REFERÊNCIAS}

ALMEIDA CORPORATE LAW. Fusões e aquisições: breves estudos. São Paulo: Almeida Corporate Law, [2009]. Disponível em: http://www.almeidalaw.com.br/download/Estudo\%20Fusoes\%20Final.pdf. Acesso em: 29 nov. 2020.

ANGWIN, Duncan. Mergers and acquisitions across European borders: National perspectives on preacquisition due diligence and the use of professional advisers. Journal of world business, v. 36, n. 1, p. 32-57, 2001.

ASSOCIAÇÃO BRASILEIRA DAS ENTIDADES DOS MERCADOS FINANCEIRO E DE CAPITAIS (AMBINA). Anúncios de fusões e aquisições registram aumento de $\mathbf{2 0 , 0 \%}$ no ano. Rio de Janeiro: AMBINA, 2019. Disponível em: 
https://www.anbima.com.br/pt_br/informar/relatorios/mercado-de-capitais/boletim-de-fusoese-aquisicoes/integra.htm. Acesso em: 20 maio 2019.

BAKER McKENZIE. Global private F\&A guide: transactional powerhouse: leading and closing three deals a day. Chicago: Baker McKenzie, 2020. Disponível em: https://www.bakermckenzie.com/en/insight/publications/2019/03/global-private-ma-guide. Acesso em: 20 jul. 2020.

BOTREL, Sérgio. Fusões e aquisições. 3. ed. São Paulo: Saraiva, 2014. p. 270.

BOUÇAS, Cibelle. Ambev compra mineira Wäls e a integra à Bohemia. In: SOCIEDADE BRASILEIRA DE VAREJO E CONSUMO (SBVC). Notícias. São Paulo, 11 fev. 2015. Disponível em: http://sbvc.com.br/1889394-ambev-compra-mineira-wals-e-a-integra-abohemia/. Acesso em: 30 nov. 2020.

BRASIL. Lei $\mathrm{n}^{\mathbf{0}}$ 10.406, de 10 de janeiro de 2002. Institui o Código Civil. Brasília, DF: Presidência da República, 2002. Disponível em: http://www.planalto.gov.br/ccivil_03/leis/2002/L10406compilada.htm. Acesso em: 29 set. 2020.

BRASIL. Lei $\mathbf{n}^{\mathbf{0}}$ 11.638, de 28 de dezembro de 2007. Altera e revoga dispositivos da Lei no 6.404, de 15 de dezembro de 1976, e da Lei no 6.385, de 7 de dezembro de 1976, e estende às sociedades de grande porte disposições relativas à elaboração e divulgação de demonstrações financeiras. Brasília, DF: Presidência da República, 2007. Disponível em: http://www.planalto.gov.br/ccivil_03/_ato2007-2010/2007/lei/111638.htm. Acesso em: 29 set. 2020.

BRASIL. Lei $\mathbf{n}^{\circ}$ 11.941, de 27 de maio de 2009. Altera a legislação tributária federal relativa ao parcelamento ordinário de débitos tributários; concede remissão nos casos em que especifica; institui regime tributário de transição, alterando o Decreto no 70.235, de 6 de março de 1972, as Leis nos 8.212, de 24 de julho de 1991, 8.213, de 24 de julho de 1991, 8.218 , de 29 de agosto de 1991, 9.249, de 26 de dezembro de 1995, 9.430, de 27 de dezembro de 1996, 9.469, de 10 de julho de 1997, 9.532, de 10 de dezembro de 1997, 10.426, de 24 de abril de 2002, 10.480, de 2 de julho de 2002, 10.522, de 19 de julho de 2002, 10.887, de 18 de junho de 2004, e 6.404, de 15 de dezembro de 1976, o Decreto-Lei no 1.598, de 26 de dezembro de 1977, e as Leis nos 8.981, de 20 de janeiro de $1995,10.925$, de 23 de julho de $2004,10.637$, de 30 de dezembro de 2002, 10.833, de 29 de dezembro de 2003, 11.116, de 18 de maio de 2005, 11.732, de 30 de junho de 2008, 10.260, de 12 de julho de 2001, 9.873, de 23 de novembro de 1999, 11.171, de 2 de setembro de 2005, 11.345, de 14 de setembro de 2006; prorroga a vigência da Lei no 8.989, de 24 de fevereiro de 1995; revoga dispositivos das Leis nos 8.383, de 30 de dezembro de 1991, e 8.620, de 5 de janeiro de 1993, do DecretoLei no 73, de 21 de novembro de 1966, das Leis nos 10.190, de 14 de fevereiro de 2001, 9.718, de 27 de novembro de 1998, e 6.938, de 31 de agosto de 1981, 9.964, de 10 de abril de 2000, e, a partir da instalação do Conselho Administrativo de Recursos Fiscais, os Decretos nos 83.304, de 28 de março de 1979, e 89.892, de 2 de julho de 1984, e o art. 112 da Lei no 11.196, de 21 de novembro de 2005; e dá outras providências. Brasília, DF: Presidência da República, 2009. Disponível em: http://www.planalto.gov.br/ccivil_03/_ato20072010/2009/lei/111941.htm. Acesso em: 29 set. 2020.

BRASIL. Lei $\mathbf{n}^{\circ}$ 6.404, de 15 de dezembro de 1976. Dispõe sobre as Sociedades por Ações. Brasília, DF: Presidência da República, 1976. Disponível em: http://www.planalto.gov.br/ccivil_03/leis/16404consol.htm. Acesso em: 29 set. 2020. 
BRASIL. Lei $\mathbf{n}^{\circ}$ 6.404, de 15 de dezembro de 1976. Dispõe sobre as Sociedades por Ações. Brasília, DF: Presidência da República, 1976. Disponível em: http://www.planalto.gov.br/ccivil_03/leis/16404consol.htm. Acesso em: 29 set. 2020.

BREALEY, Richard A.; MYERS, Stewart C. Finanças corporativas: investimento de capital e avaliação. 2006.

BROOKES, Molly. The Seller-Friendly Approach to MAC Clause Analysis Should Be Replaced by a Reality-Friendly Approach. U. Det. Mercy L. Rev., v. 87, p. 83, 2009.

CARVALHOSA, Modesto. Eficácia e execução específica do acordo de acionistas. Revista da EMERJ, v. 26, p. 125-32, 2004.

CHERTOK, Adam B. Rethinking the US Approach to Material Adverse Change Clauses in Merger Agreements. U. Miami Int'l \& Comp. L. Rev., v. 19, p. 99, 2011.

COASE, Ronald Harry. The nature of the firm. In: Essential readings in economics. Palgrave, London, 1995. p. 37-54.

COATES, John C. Allocating risk through contract: Evidence from M\&A and policy implications. 2012.

COELHO, Fábio Ulhoa. Curso de Direito Comercial, Volume 2: Direito de Empresa . Editora Saraiva, 2000.

COMITÊ DE PRONUNCIAMENTOS CONTÁBEIS (CPC). Pronunciamento técnico CPC 15 (R1): combinação de negócios. Brasília, DF: CPC, 2011. Disponível em: http://static.cpc.aatb.com.br/Documentos/235_CPC_15_R1_rev\%2004.pdf. Acesso em: 29 set. 2020. p. 21.

CRIMMINS, Paul M. et al. Earn-outs in M\&A Transactions: Key Structures and Recent Developments. M\&A Journal: Independent Report Deals Dealmakers. https://www. mayerbrown. com/Files/Publication/5b829276-5f8b-4a5a-ad5fa492e73d6574/Presentation/PublicationAttachment/a5e9717d-c9d1-4c00-be87828ef83e4776/Earn-outs_MA. pdf, 2009.

DEPAMPHILIS, Donald. Mergers, acquisitions, and other restructuring activities: An integrated approach to process, tools, cases, and solutions. Academic Press, 2019.

ELSON, Charles M. The Art of M \& A Due Diligence: Navigating Critical Steps and Uncovering Crucial Data. McGraw-Hill, 2010.

FIRTH, Michael. Takeovers, shareholder returns, and the theory of the firm. The Quarterly Journal of Economics, v. 94, n. 2, p. 235-260, 1980.

Fusões e aquisições no Brasil: outubro 2019. In: PWC Brasil. [São Paulo], nov. 2019. Disponível em: https://www.pwc.com.br/pt/estudos/servicos/assessoria-tributariasocietaria/fusoes-aquisicoes/2019/fusoes-e-aquisicoes-no-brasil-outubro.html. Acesso em: 26 nov. 2019.

GILSON, Ronald J. Value creation by business lawyers: Legal skills and asset pricing. The Yale Law Journal, v. 94, n. 2, p. 239-313, 1984.

GILSON, Ronald J.; BLACK, Bernard S. The law and finance of corporate acquisitions. Westbury, NY: Foundation Press, 1995.

IAN DE PORTO ALEGRE MUNIZ; BRANCO, Adriano Castello. Fusões e aquisições: aspectos fiscais e societários. Quartier Latin, 2007. 
JOHNSON, Gerry; SCHOLES, Kevan; WHITTINGTON, Richard. Exploring corporate strategy: text \& cases. Pearson education, 2009.DAMODARAN, Aswath. The value of synergy. Available at SSRN 841486, 2005.

LAAMANEN, Tomi; BRAUER, Matthias; JUNNA, Olli. Performance of acquirers of divested assets: Evidence from the US. software industry. Strategic Management Journal, v. 35, n. 6, p. 914-925, 2014.

LUIZE, Marcelo Shima. Cláusula de indenização e resolução contratual em operações de fusão e aquisição: necessidade ou mera reprodução do modelo anglo-saxão?. In: KLEINDIENST, Ana Cristina (coord.). Estudos aplicados de direito empresarial: societário. São Paulo: Almedina, 2016. p. 145.

PEPPERDINE UNIVERSITY. Pepperdine Private Capital Markets Project 2017. Disponível https://bschool.pepperdine.edu/about/people/faculty/appliedresearch/research/pcmsurvey/cont ent/private-capitalmarkets-report-2017.pdf. Acesso em: 24 jul. 2019.

REED, Stanley Foster; LAJOUX, Alexandra Reed; NESVOLD, H. Peter. The Art of M \& A: A Merger Acquisition Buyout Guide. McGraw Hill, 2007.

ROSS, Stephen A. et al. Administração financeira. AMGH Editora, 2015.

SÁ, Fernando O. A determinação contingente do preço de aquisição de uma empresa através da cláusula de earn-out. In: Aquisição de empresa. 1a . Ed, Coimbra Editora S.A, 2011.

SALAMA, Bruno Meyerhof. Análise econômica da arbitragem. In: TIMM, Luciano Benetti (org.). Direito e economia no Brasil. São Paulo: Atlas, 2012. p. 384-385.

SHAVELL, Steven. Alternative dispute resolution: an economic analysis. The Journal of Legal Studies, v. 24, n. 1, p. 1-28, 1995.

TIMM, Luciano Benetti. Arbitragem nos contratos empresariais, internacionais e governamentais. Porto Alegre: Livraria do Advogado, 2009. p. 23.

TIMM, Luciano Benetti; JOBIM, Eduardo. A arbitragem, os contratos empresariais e a interpretação econômica do direito. Direito \& Justiça, v. 33, n. 1, p. 80-97, 2007.

WEST, Glenn. Avoiding the mindless use of the brainless MAC clause. In: GLOBAL PRIVATE EQUITY WATCH. Features. [New York], 7 ago. 2017. Disponível em: https://privateequity.weil.com/features/avoiding-mindless-use-mac-clause/. Acesso em: 29 nov. 2020.

WESTON, J. Fred; BRIGHAM, Eugene F. Fundamentos da administração financeira. 2000 .

WILLIAMSON, Oliver E. Transaction cost economics and organization theory. Industrial and corporate change, v. 2, n. 2, p. 107-156, 1993.

XIA, Jun; LI, Sali. The divestiture of acquired subunits: A resource dependence approach. Strategic Management Journal, v. 34, n. 2, p. 131-148, 2013. GHEMAWAT, Pankai; GHADAR, Fariborz. The dubious logic of global megamergers. Harvard Business, 2000. 